\title{
Inflammation management in acute diverticulitis: current perspectives
}

This article was published in the following Dove Press journal: Journal of Inflammation Research

\section{Marco Ceresoli',2 \\ Giulia Lo Bianco ${ }^{1,2}$ \\ Luca Gianotti ${ }^{1,2}$ \\ Luca Nespoli',2}

'Department of General Surgery, San Gerardo Hospital, University of Milano-Bicocca, Monza, Italy; ${ }^{2}$ School of Medicine and Surgery, University of Milano-Bicocca, Milan, Italy
Correspondence: Luca Nespoli Department of General Surgery, San Gerardo Hospital, University of Milano-Bicocca, via Pergolesi 33, 20900 Monza, Italy

Tel +3939233365I

Email luca.nespoli@unimib.it

\begin{abstract}
The pathogenesis of diverticular disease and acute diverticulitis is still unclear and many different hypotheses have been formulated. Seemingly, there are several related factors such as chronic inflammation, gut microbiome, obesity and the immunogenic properties of fat tissue and diet. Inflammation plays a pivotal role in diverticular disease and acute diverticulitis. The aim of the present review is to investigate the role of inflammation in diverticular disease as well as in mild and complicated acute diverticulitis with a focus on current research and treatment perspectives.
\end{abstract}

Keywords: acute diverticulitis, inflammation, diverticular disease.

\section{Introduction}

Colonic diverticulosis is an increasingly common condition in the aging western population. Prevalence is as high as $71.4 \%$ in those aged over 80 years, with an equal sex distribution and a preferential localization to the left colon, when compared with Asian countries where diverticulosis is typically right sided. The term diverticulosis refers to the presence of diverticula due to the out-pouching of mucosa and muscularis mucosa through the muscularis propria at sites of vascular penetration. ${ }^{1}$ Diverticular disease comprehends a large spectrum of manifestations varying from the presence of persistent abdominal symptoms without verifiable inflammation (symptomatic uncomplicated diverticular disease [SUDD]) to a significant and symptomatic inflammatory process (segmental colitis associated with diverticulosis and diverticulitis. ${ }^{2}$ According to the latest figures, $1 \%-4 \%$ of patients with diverticulosis progress to diverticulitis. Acute diverticulitis is a serious and potentially life-threatening condition. It can be classified as "mild" or "severe" according to Ambrosetti CT criteria or according to the modified Hinchey classification (Table 1 ). In $\sim 85 \%$ of cases, diverticulitis can be treated conservatively, while a $15 \%$ of cases require surgical intervention or percutaneous drainage. ${ }^{3}$ It is regarded as the most common cause for colorectal perforation and is associated with a substantial mortality rate during emergency surgery, which is estimated around $10 \%$ in Hinchey III and Hinchey IV stage.

The aim of the present review is to provide an overview of the actual knowledge on pathogenesis and treatment of diverticular inflammation in uncomplicated and complicated situations. 
Table I Acute diverticulitis classifications

\begin{tabular}{ll}
\hline Stage & Description \\
\hline Modified Hinchey classification \\
0 & Mild clinical diverticulitis \\
la & Confined pericolic inflammation or phlegmon \\
Ib & Confined pericolic abscess \\
II & Pelvic, distant intra-abdominal or retroperitoneal abscess \\
III & Generalized purulent peritonitis \\
IV & Generalized fecal peritonitis \\
Ambrosetti's classification \\
Mild & -Wall thickening $>5$ mm \\
& - Pericolic fat stranding \\
Severe & - Abscess \\
& -Extraluminal air \\
& - Extraluminal contrast
\end{tabular}

\section{Pathogenesis of diverticular inflammation}

The process leading to diverticulitis was traditionally linked to that causing appendicitis with the diverticulum becoming obstructed by inspissated stool eventually leading to its perforation. Recently, advances in research have shed a new light on this condition shattering the dogma of tradition and suggesting different approaches to its management.

Some authors have demonstrated the presence of chronic low-grade inflammation in the mucosa harboring diverticula in patients who did not suffer from acute diverticulitis. ${ }^{4}$ Further studies have confirmed the presence of microscopic colitis on biopsy material in diverticular disease, with the degree of inflammatory infiltration seemingly related to the severity of the condition. ${ }^{5}$ Notably, a systematic appraisal of clinical, radiological, laboratory and endoscopic aspects of 50 consecutive cases of diverticulitis found that, in uncomplicated forms, inflammation was mostly confined to the mucosa with no signs of pericolonic disease at CT, much to the detriment of the micro-perforation theory. ${ }^{6}$ The consequences of inflammation are muscular hypertrophy and enteric nerve remodeling leading to visceral hypersensitivity and altered motility. ${ }^{7,8}$ At molecular level, recent studies have identified increased amounts of matrix metalloproteinases and pro-inflammatory cytokines as well as alterations in neuropeptides and in the serotoninergic signaling pathways. ${ }^{9-11}$ Voluptuary habits typically linked to inflammation such as smoking and consuming alcohol have also been associated to this condition. Several studies have demonstrated an augmented incidence of acute diverticulitis in smokers and alcohol consumers. ${ }^{12}$ The use of non steroidal anti inflammatory drugs (NSAIDs), such as aspirin, also seems to play a role in the development of acute diverticulitis. A large population study with 22 years of follow-up demonstrated a higher incidence of acute diverticulitis in patients treated with aspirin. ${ }^{13}$ This could be due to direct topical injury and/or to impaired prostaglandin synthesis with mucosal impairment and enhanced permeability to toxins and bacteria.

These inflammatory changes could be at the base of the continued symptoms and altered bowel habits that are described following acute attacks in symptomatic uncomplicated diverticular disease (SUDD). In this context, diverticular disease should no longer be considered an asymptotic condition hampered by occasional acute episodes. It should, instead, be considered a form of inflammatory bowel syndrome where a long-term history of chronic inflammation may lead to diverticulitis, first uncomplicated (confined to the bowel wall) and then complicated.

While diverticulosis is more common in the aging population and equally distributed between the two sexes, diverticulitis episodes are seemingly more common in the younger age groups, where the prevalence rate of male patients is more. Obesity, an increased BMI or increased circumference and waist-to-hip ratio are linked to an enhanced risk of developing diverticulitis and its complications; ${ }^{14}$ interesting hypothesis were put forward regarding the immunologic role of the fat tissue surrounding the viscera. ${ }^{15}$ The role of a reduced dietary fiber intake in both diverticulosis and diverticular disease has been much re-dimensioned. Although the original Painter theory was supported by a few studies, there seems to be a lack of robust favorable evidence and presence of some contradictory reports. ${ }^{16}$ Common advice that was given to patients with diverticular disease to consume a low residue diet, and especially to avoid nuts, corn and popcorn in order to prevent diverticula inflammation and bleeding, has also been proved unfounded. ${ }^{17}$ Some authors have argued that the type of fiber more than the amount itself may influence inflammatory response by altering the intestinal microbiome, an element that is gaining growing attention among experts. The composition of gut microbiota is characteristic of each individual and may be influenced by many different factors. ${ }^{18}$ The gut mucosal barrier has protective functions and is involved in controlling cell proliferation and in the homeostasis of the immune system. It also has metabolic functions such as the fermentation of dietary residues in short chain fatty acids. Gut microbiome is known to be altered in a number of pathologic conditions such as colonic cancer, appendicitis and, notably, Inflammatory Bowel Disease. ${ }^{19}$ Recent studies have identified significant changes in the microbiome of patients suffering from diverticular disease such as an excess of mucus degrading species. ${ }^{20} \mathrm{~A}$ significant difference in the levels of Akkermansia muciniphila, which produces a variety of products of fermentation, was also noted. ${ }^{21}$ Overall, these changes may cause both mucosal 
inflammation and gut sensitivity and motility changes that are found in diverticular disease. The amount and composition of dietary fibers and obesity, factors that are both associated with diverticular disease and diverticulitis, have also been found to be linked with microflora alterations. This has brought to the formulation of a new hypothesis that encompasses the roles of chronic low-grade inflammation and altered gut microbiota as the possible causes behind diverticular disease and its chronic symptoms and as the potential triggers of acute diverticulitis. ${ }^{22}$

\section{Antibiotic therapy in acute uncomplicated diverticulitis}

The traditional standard treatment for acute uncomplicated diverticulitis included bowel rest, intravenous fluids and intravenous antibiotics. The use of antibiotics was based on the long-standing (and currently much questioned) premise that diverticulitis was caused by microcolonic perforation; however, antibiotic therapy has now become controversial. A recent extensive meta-analysis has shown that evidence in support of this kind of therapy is scarce and of low quality. ${ }^{23}$ The authors found no randomized controlled trial (RCT) studies in support of antibiotic treatment, and there is only one small, retrospective study that showed no difference in time to recovery and risk of recurrence. These findings were confirmed by a further observational study and by one vast multicenter trial. ${ }^{24,25}$ The latter randomized a group of 623 patients to treatment with or without antibiotics and showed no difference with regard to rate of complication or need for surgery and similar trends for subjective outcomes such as abdominal pain and tenderness, concluding that antibiotic therapy neither accelerates recovery nor prevents complications in acute uncomplicated diverticulitis. There were some methodological drawbacks of this study such as the high number of cases of recurrent rather than primary diverticulitis, the long accrual period and the non-standardized antibiotic therapy, which may have resulted in performance bias and further research was deemed necessary. In 2017, a second multicenter RCT was conducted, which included 528 patients, who at their first episode of acute diverticulitis were randomized to either observation alone or antibiotic treatment according to a well-defined scheme. ${ }^{26}$ The study showed longer initial admission and a higher rate of antibiotic-related adverse events in the antibiotic group. No differences were found in time for recovery, complications, ongoing diverticulitis, sigmoid resections, recurrence, rate of readmission and mortality. Based on these results, the authors concluded that antibiotics can be safely omitted in patients with a first episode of uncomplicated (Hinchey Ia) left-sided diverticulitis. Similar results were found for Hinchey Ib diverticulitis. However, since the trial lacked power to detect smaller subgroup effects and there are no other reports in literature, the authors concluded that observational treatment should be, for the moment, limited to Hinchey Ia cases until larger Hinchey Ib samples have been examined.

\section{Anti-inflammatory compounds}

\section{Anti-inflammatory compounds in SUDD}

Mesalamine is a 5-aminosalicylic acid preparation employed in the treatment of inflammatory gastrointestinal disorders. It is known to be effective in inducing and maintaining remission in ulcerative colitis and preventing relapse after surgically induced remission in Crohn's disease. Although its molecular action has not been fully elucidated, mesalamine seems to exert an inhibitory activity on the inflammatory cascade, reducing the production of interleukin-1 and free radicals. ${ }^{27}$ The potential benefit of mesalamine administration has been mostly evaluated in the context of SUDD and in prevention of acute episodes. Several randomized studies investigated the role of mesalamine in treatment of SUDD symptoms and in prevention of recurrences. ${ }^{28-37}$ Their results were summarized in a systematic review by Picchio et al. ${ }^{38}$ When compared with placebo or high-fiber diet, mesalamine seemed to obtain better results in symptom relief. However it should be noticed, as shown in Table 2, that the included trials have different design, different treatment and different follow-up durations. No data are available to meta-analyze results. Moreover it should be noticed that the definition of SUDD is still unclear: despite Tursi et al proposing some objective criteria to define SUDD with an endoscopic-based score, the majority of the studies available did not apply this criteria and the definition of SUDD is very variable giving a high heterogeneity among the studies. ${ }^{39}$

\section{Anti-inflammatory compounds in acute diverticulitis}

Meanwhile, the effect of mesalamine on acute inflammation has been little researched. One small retrospective series suggested a possible role for mesalamine in modulating acute inflammatory response in patients suffering from uncomplicated diverticulitis. ${ }^{40}$ In this single-center cohort study, 50 patients with a CT-confirmed diagnosis of acute uncomplicated diverticulitis received $3.2 \mathrm{~g} / \mathrm{d}$ of mesalamine or standard therapy from the day of admission. Mesalamine administration was associated with a trend toward a faster resolution of inflammation (by means of C-reactive plasma level over time) as well as with an earlier reintroduction of food intake and a shorter hospital stay. 
Table 2 Randomized studies on mesalamine in SUDD

\begin{tabular}{|c|c|c|c|c|c|c|c|}
\hline Study ID & $\begin{array}{l}\text { Included } \\
\text { patients }\end{array}$ & $\begin{array}{l}\text { Study's } \\
\text { interventions }\end{array}$ & $\begin{array}{l}\text { Number of } \\
\text { patients }\end{array}$ & Endpoint & Follow-up & Results & Note \\
\hline Kruis et $\mathrm{al}^{\mid 31}$ & SUDD & $\begin{array}{l}\text { Mesalamine } 3 \mathrm{~g} / \mathrm{d} \text { vs } \\
\text { placebo }\end{array}$ & $56+61$ & $\begin{array}{l}\text { Pain intensity } \\
\text { reduction }\end{array}$ & I month & No difference & \\
\hline Tursi et $\mathrm{al}^{34}$ & SUDD & $\begin{array}{l}\text { Mesalamine vs } \\
\text { mesalamine }+ \\
\text { Lactobacillus casei vs } \\
\text { L. casei vs placebo }\end{array}$ & $5 I+55+54+50$ & $\begin{array}{l}\text { Prevention of SUDD } \\
\text { recurrence }\end{array}$ & 12 months & $\begin{array}{l}\text { Mesalamine and } \\
\text { L. casei reduced } \\
\text { recurrences; better } \\
\text { in combination }\end{array}$ & \\
\hline Smith et al ${ }^{36}$ & SUDD & $\begin{array}{l}\text { Mesalamine vs } \\
\text { placebo }\end{array}$ & $18+14$ & $\begin{array}{l}\text { Symptoms relief and } \\
\text { inflammatory genes } \\
\text { expression }\end{array}$ & 3 months & $\begin{array}{l}\text { Reduction with } \\
\text { mesalamine }\end{array}$ & $\begin{array}{l}\text { Study } \\
\text { unpublished }\end{array}$ \\
\hline Trepsi et a ${ }^{37}$ & SUDD & $\begin{array}{l}\text { Mesalamine vs } \\
\text { placebo }\end{array}$ & $81+85$ & $\begin{array}{l}\text { Prevention of } \\
\text { recurrence and } \\
\text { complications }\end{array}$ & 5 years & $\begin{array}{l}\text { Significant reduction } \\
\text { with mesalamine }\end{array}$ & \\
\hline $\begin{array}{l}\text { Di Mario } \\
\text { et } \mathrm{al}^{33}\end{array}$ & SUDD & $\begin{array}{l}\text { Mesalamine } 800 \text { vs } \\
\text { mesalamine } 1600 \\
\text { vs rifaximin } 400 \text { vs } \\
\text { rifaximin } 800\end{array}$ & $39+43+40+48$ & Symptoms relief & 3 months & $\begin{array}{l}\text { Mesalamine similar } \\
\text { to rifaximin }\end{array}$ & $\begin{array}{l}\text { **Duplicate } \\
\text { publication }\end{array}$ \\
\hline Tursi et $\mathrm{al}^{35}$ & SUDD & $\begin{array}{l}\text { Mesalamine vs } \\
\text { mesalamine }+ \text { L. casei } \\
\text { vs } L \text {. casei }\end{array}$ & $27+29+29$ & $\begin{array}{l}\text { Prevention of SUDD } \\
\text { recurrence }\end{array}$ & 12 months & $\begin{array}{l}\text { Mesalamine }+L . \\
\text { casei better than } \\
\text { single agent }\end{array}$ & \\
\hline $\begin{array}{l}\text { Comparato } \\
\text { et } \mathrm{al}^{32}\end{array}$ & SUDD & $\begin{array}{l}\text { Mesalamine } 800 \text { vs } \\
\text { mesalamine } 1600 \\
\text { vs rifaximin } 400 \text { vs } \\
\text { rifaximin } 800\end{array}$ & $66+69+67+66$ & Symptoms relief & 12 months & $\begin{array}{l}\text { Mesalamine similar } \\
\text { to rifaximin }\end{array}$ & $\begin{array}{l}\text { **Duplicate } \\
\text { publication }\end{array}$ \\
\hline $\begin{array}{l}\text { Stollman } \\
\text { et } \mathrm{al}^{28}\end{array}$ & $\begin{array}{l}\text { Uncomplicated } \\
\text { acute diverticulitis }\end{array}$ & $\begin{array}{l}\text { Mesalamine vs } \\
\text { mesalamine }+ \\
\text { Bifidobacterium } \\
\text { infantis vs placebo }\end{array}$ & $40+36+41$ & $\begin{array}{l}\text { Symptoms relief at } 3 \\
\text { months }\end{array}$ & 12 months & $\begin{array}{l}\text { No differences } \\
\text { among groups }\end{array}$ & \\
\hline Parente et $\mathrm{a}^{29}$ & $\begin{array}{l}\text { Previous } \\
\text { uncomplicated } \\
\text { acute diverticulitis }\end{array}$ & $\begin{array}{l}\text { Mesalamine vs } \\
\text { placebo }\end{array}$ & $45+47$ & $\begin{array}{l}\text { Diverticulitis } \\
\text { recurrence }\end{array}$ & 24 months & No difference & \\
\hline Raskin et $\mathrm{a}^{30}$ & $\begin{array}{l}\text { Previous } \\
\text { uncomplicated } \\
\text { acute diverticulitis }\end{array}$ & $\begin{array}{l}\text { Mesalamine } 1,2 \text { vs } \\
\text { mesalamine } 2,4 \text { vs } \\
\text { mesalamine } 4,8 \text { vs } \\
\text { placebo }\end{array}$ & $291+290+299+289$ & $\begin{array}{l}\text { Diverticulitis } \\
\text { recurrence }\end{array}$ & 24 months & No differences & \\
\hline
\end{tabular}

Note: **Duplicate publication.

Abbreviation: SUDD, symptomatic uncomplicated diverticular disease.

Mesalamine has also been studied in preventing recurrence of acute diverticulitis after a first episode. Khan et al published a letter containing results of a meta-analysis that demonstrated that mesalamine has no role in prevention of acute diverticulitis: ${ }^{41}$ however it should be noticed that two of the included studies considered as recurrent only diverticulitis episodes requiring surgery and not episodes of mild inflammation; results should be interpreted with caution. Moreover, heterogeneity of data is very high and the level of evidence available is low. Table 2 summarizes the results of all available randomized trials on administration of mesalamine in SUDD.

\section{Probiotics in SUDD}

The role of probiotics as modulators of immune system and chronic inflammation has been investigated. At the moment, probiotics are considered as a third choice for the treatment of
SUDD and no evidences exist in the treatment and prevention of acute diverticulitis. Some studies, summarized by Elisei and Tursi in a systematic review, seem to demonstrate a role in reduction of SUDD recurrence. ${ }^{42}$

\section{Complicated acute diverticulitis}

Complicated acute diverticulitis comprehends all forms of acute inflammation of the sigmoid colon bearing diverticula with a localization not restricted to the intestinal wall or pericolic fat. It can be characterized by the presence of near or distant abscess (stages Ib and II) or by the presence of purulent or fecaloid diffuse peritonitis (stages III and IV).

In these stages of pathology, the acute process is no more confined to the sigmoid colon and can no longer be considered as an isolated inflammatory process. The acute inflammation of the diverticular wall, consisting only of mucosa 
and submucosa without a muscular layer, leads to parietal edema with disaggregation of the normal stratification with micro-perforations or macro-perforations and bacterial translocation and subsequent peritoneal or extraperitoneal (based on the diverticulum location) bacterial contamination. ${ }^{43}$ When bacterial contamination over-reaches the peritoneal capacity to drain fluids and remove contaminants through the lymphatic system, it leads to intra abdominal sepsis and peritonitis. ${ }^{44}$ Several factors contribute to the development of intraperitoneal sepsis and diffused peritonitis such as virulence, the characteristics and the bacterial load of the contaminant bacteria, the immune status of the patient and elements of the local environment such as the presence of fecal material and/or blood. The presence of bacteria-producing endotoxins in the peritoneal cavity induces a violent and intense activation of the inflammatory response with cytokine release and a cellular and humoral response. All of these alterations of the normal physiology of the peritoneum, with the release of cytokines, activation and mis-regulation of the immune response contribute to the development of a systemic inflammatory response syndrome that can also lead to multiple organ failure unless the septic source is timely removed and controlled. ${ }^{44,45}$ Therefore, treatment of acute diverticulitis should be targeted to the control and removal of the septic source that maintains inflammatory response. According to the extent of inflammation and extension of the involvement of the peritoneal cavity, several approaches have been proposed. Antibiotic therapy is always mandatory due to the presence of bacterial contamination through the visceral wall systemic. ${ }^{46,47}$

\section{Percutaneous drainage}

In a considerable proportion of patients, acute diverticulitis associates with abscess formation, near (Hinchey Ib) or distant (Hincey II) to the diverticula according to the modified Hinchey classification. ${ }^{48}$ The treatment of abscess requires antibiotic therapy. If the abscess is limited in size (generally $<4 \mathrm{~cm}$ in diameter), systemic antibiotic therapy alone is considered safe and effective in removing the abscess and solving acute inflammation with a pooled failure rate of $20 \%$ and a mortality rate of $0.6 \%{ }^{49}$ When abscess diameter is larger (generally $>4 \mathrm{~cm}$ ), antibiotics could fail to reach the needed concentration inside the abscess leading to an augmented failure rate. ${ }^{50}$ Historically, the presence of big abscesses was considered an indication to surgery. In the late 1980s, with the development of US-guided techniques, percutaneous drainage of abscesses has been proposed an alternative to surgery, with exciting results. ${ }^{51-54}$ The rationale of this technique is the drainage and removal the localized intra-abdominal bacterial contamination without the need for a surgical operation. Several studies have been published reporting the results of percutaneous drainage of abscesses; a recent systematic review including 684 patients with abscess (median diameter of $6.1 \mathrm{~cm}$ ) calculated a failure rate of $20.8 \%$ with an associated mortality of $1.6 \%{ }^{49}$ It should be noticed that, presently, there are no randomized studies available on the best treatment of intra-abdominal abscess from acute diverticulitis but only observational studies are available. When the patient's clinical conditions allow it (in the absence of severe sepsis and septic shock) and percutaneous drainage is not feasible, antibiotic therapy alone can be considered, keeping in mind the high failure rate and the subsequent need for surgical control of the septic source.

\section{Laparoscopic lavage}

When the peritoneal defenses cannot control bacterial contamination from a perforated/inflamed diverticulum and confine it into an abscess, diffuse peritonitis occurs. ${ }^{44}$ Diffuse peritonitis can by characterized by the presence of purulent exudates (stage III according to the Hinchey classification) or diffused fecaloid material (stage IV). In these cases, surgical exploration is mandatory to control and remove the source of infection that maintains the inflammatory response. Traditionally, in case of peritonitis from acute diverticulitis, Hartmann procedure is the treatment of choice. However, emergency surgery is associated with high morbidity $(30 \%-50 \%)$ and mortality $(10 \%-20 \%) .{ }^{55,56}$ Because of this, and in order to limit surgical intervention only to source control avoiding bowel resection and the confection of stoma, a laparoscopic approach with lavage, drainage and no resection has been proposed as an alternative in purulent diffused peritonitis (Hinchey III). ${ }^{57}$ The first report of this technique in a large prospective cohort of patients showed a very low morbidity and mortality ( $4 \%$ and $3 \%$, respectively) proving its feasibility. The procedure consists of explorative laparoscopy: if no macroscopic defects are found in the colonic wall, only an abundant lavage with warm saline water is performed, with no resection. The debate about this promising technique arose immediately and four RCTs have been launched to investigate the issue since. Presently, the results of three trials have been published, with contrasting results. ${ }^{58-60}$ Immediately after publication, these results have been summarized in six different meta-analyses with similar findings. ${ }^{61-66}$ When compared with emergency surgery with resection, laparoscopic lavage in Hinchey III acute diverticulitis shows a 
comparable mortality ( $3 \%$ vs $3.5 \%$ ) but is associated with a $17 \%$ failure rate with a significantly augmented need for reoperation due to the failure of the treatment and to intra-abdominal abscess formation. Long-term results were similar, with no difference in morbidity and mortality. This technique is associated with a lower number of patients receiving stoma. ${ }^{67}$ Several controversies remain about this innovative approach: despite the low mortality and the promising long-term results associated to it, laparoscopic lavage fails in one of every five patients, exposing to a scarce source control and an increased risk of sepsis. For these reasons, laparoscopic lavage with drain should be considered as a valid alternative to colonic resection only in selected patients who can tolerate the failure of the treatment and the possible incomplete control of the septic source.

\section{Damage control surgery}

Emergency surgery has borrowed from Trauma surgery the concept of damage control. When the conditions of the patients are critical, surgical intervention must be quick to allow for the timely restoration of vital functions. In these cases, the abdomen can be left open in view of a planned re-intervention when it is stabilized. ${ }^{68,69}$ The open abdomen, especially with drains or negative pressure wound therapy as a temporary abdominal closure technique allows an adjunctive function: several studies in swine models of abdominal sepsis demonstrated that vacuum-assisted closure allows for a more effective drainage of the abdominal cavity with better modulation of the inflammatory response and for a significant reduction in pro-inflammatory cytokines with a reduced rate of multiple organ failure and mortality. ${ }^{70-73}$ The reduction of intra-peritoneal levels of pro-inflammatory cytokines is also associated with a reduction of circulating systemic cytokines with an improved cardiac, pulmonary and renal function. ${ }^{71}$

The concept of damage control laparotomy has also been proposed and studied in patients with disseminated peritonitis after diverticular perforation. ${ }^{74-76}$ After the first laparotomy with resection and lavage, the two colonic stumps are abandoned and the abdomen is left open until the planned revision with anastomosis or stoma and closure if the situation allows it. This strategy in the setting of acute diverticulitis has been proposed for two reasons: to treat critically ill patients and to avoid stoma confection at the first laparotomy. Waiting for a reduction of the local inflammation might allow for a later anastomosis. Sohn et al performed a case-control study comparing traditional strategy vs damage control: there were no differences in morbidity and mortality but there was a significant reduction of stoma confection in the damage control group. ${ }^{76}$ Despite this results, obtained in a relatively small number of patients, it should be kept in mind that open abdomen is associated with several drawbacks such as the formation of enteroatmospheric fistula and high costs; guidelines recommend this strategy only in critically ill patients who cannot withstand major surgery. ${ }^{47}$

\section{Conclusion}

In conclusion, the pathogenesis of diverticular disease and acute diverticulitis is a present and still evolving issue with several interesting perspectives. The role of chronic inflammation, the interaction of human microbiota with the mucosa and the immune system, the immunogenic role of fat tissue and the role of acute inflammation should be well defined and clarified. Inflammation plays a pivotal role in the development of diverticular disease and in the acute phase of diverticulitis. Several well-designed studies are needed to clarify the real pathogenesis of diverticular disease and the role of anti-inflammatory compounds in all the disease phases, from prevention to treatment.

\section{Disclosure}

The authors report no conflicts of interest in this work.

\section{References}

1. Everhart JE, Ruhl CE. Burden of digestive diseases in the United States Part III: liver, biliary tract, and pancreas. Gastroenterology. 2009;136(4):1134-1144.

2. Strate LL, Modi R, Cohen E, Spiegel BM. Diverticular disease as a chronic illness: evolving epidemiologic and clinical insights. $\mathrm{Am} \mathrm{J}$ Gastroenterol. 2012;107(10):1486-1493.

3. Collins D, Winter DC. Modern concepts in diverticular disease. J Clin Gastroenterol. 2015;49(5):358-369.

4. Ghorai S, Ulbright TM, Rex DK. Endoscopic findings of diverticular inflammation in colonoscopy patients without clinical acute diverticulitis: prevalence and endoscopic spectrum. Am J Gastroenterol. 2003;98(4):802-806.

5. Tursi A, Brandimarte G, Elisei W, Inchingolo CD, Aiello F. Epithelial cell proliferation of the colonic mucosa in different degrees of colonic diverticular disease. J Clin Gastroenterol. 2006;40(4):306-311.

6. Tursi A, Brandimarte G, Giorgetti G, Elisei W, Maiorano M, Aiello F. The clinical picture of uncomplicated versus complicated diverticulitis of the colon. Dig Dis Sci. 2008;53(9):2474-2479.

7. Humes DJ, Simpson J, Smith J, et al. Visceral hypersensitivity in symptomatic diverticular disease and the role of neuropeptides and low grade inflammation. Neurogastroenterol Motil. 2012;24(4):318-e163.

8. Simpson J, Sundler F, Humes DJ, Jenkins D, Scholefield JH, Spiller RC. Post inflammatory damage to the enteric nervous system in diverticular disease and its relationship to symptoms. Neurogastroenterol Motil. 2009;21(8):e847-e858.

9. Rosemar A, Ivarsson ML, Börjesson L, Holmdahl L. Increased concentration of tissue-degrading matrix metalloproteinases and their inhibitor in complicated diverticular disease. Scand J Gastroenterol. 2007;42(2):215-220. 
10. Tursi A, Elisei W, Brandimarte G, et al. Mucosal expression of basic fibroblastic growth factor, Syndecan 1 and tumor necrosis factor-alpha in diverticular disease of the colon: a case-control study. Neurogastroenterol Motil. 2012;24(9):836-e396.

11. Böttner M, Barrenschee M, Hellwig I, et al. The enteric serotonergic system is altered in patients with diverticular disease. Gut. 2013;62(12):1753-1762.

12. Turunen P, Wikström H, Carpelan-Holmström M, Kairaluoma P, Kruuna $\mathrm{O}$, Scheinin T. Smoking increases the incidence of complicated diverticular disease of the sigmoid colon. Scand J Surg. 2010;99(1):14-17.

13. Strate LL, Liu YL, Huang ES, Giovannucci EL, Chan AT. Use of aspirin or nonsteroidal anti-inflammatory drugs increases risk for diverticulitis and diverticular bleeding. Gastroenterology. 2011;140(5):1427-1433.

14. Strate LL, Liu YL, Aldoori WH, Syngal S, Giovannucci EL. Obesity increases the risks of diverticulitis and diverticular bleeding. Gastroenterology. 2009;136(1):115-122.e1.

15. Paeschke A, Erben U, Kredel LI, Kühl AA, Siegmund B. Role of visceral fat in colonic inflammation: from Crohn's disease to diverticulitis. Curr Opin Gastroenterol. 2017;33(1):53-58.

16. Painter NS, Burkitt DP. Diverticular disease of the colon: a deficiency disease of Western civilization. Br Med J. 1971;2(5759):450-454.

17. Strate LL, Liu YL, Syngal S, Aldoori WH, Giovannucci EL. Nut, corn, and popcorn consumption and the incidence of diverticular disease. JAMA. 2008;300(8):907-914.

18. Guarner F, Malagelada JR. Gut flora in health and disease. Lancet. 2003;361(9356):512-519.

19. Swidsinski A, Loening-Baucke V, Vaneechoutte M, Doerffel Y. Active Crohn's disease and ulcerative colitis can be specifically diagnosed and monitored based on the biostructure of the fecal flora. Inflamm Bowel Dis. 2008;14(2):147-161.

20. Barbara G, Scaioli E, Barbaro MR, et al. Gut microbiota, metabolome and immune signatures in patients with uncomplicated diverticular disease. Gut. 2017;66(7):1252-1261.

21. Tursi A, Mastromarino P, Capobianco D, et al. Assessment of fecal microbiota and fecal metabolome in symptomatic uncomplicated diverticular disease of the colon. J Clin Gastroenterol. 2016;50 Suppl 1:S9-S12.

22. Ley RE, Turnbaugh PJ, Klein S, Gordon JI. Microbial ecology: human gut microbes associated with obesity. Nature. 2006;444(7122):1022-1023.

23. de Korte N, Unlü C, Boermeester MA, Cuesta MA, Vrouenreats BC, Stockmann HB. Use of antibiotics in uncomplicated diverticulitis. $\mathrm{Br}$ J Surg. 2011;98(6):761-767.

24. de Korte N, Kuyvenhoven JP, van der Peet DL, Felt-Bersma RJ, Cuesta MA, Stockmann HB. Mild colonic diverticulitis can be treated without antibiotics. A case-control study. Colorectal Dis. 2012;14(3): 325-330.

25. Chabok A, Påhlman L, Hjern F, Haapaniemi S, Smedh K; AVOD Study Group. Randomized clinical trial of antibiotics in acute uncomplicated diverticulitis. Br J Surg. 2012;99(4):532-539.

26. Daniels L, Ünlü Ç, de Korte N, et al; Dutch Diverticular Disease (3D) Collaborative Study Group. Randomized clinical trial of observational versus antibiotic treatment for a first episode of CT-proven uncomplicated acute diverticulitis. Br J Surg. 2017;104(1):52-61.

27. MacDermott RP. Progress in understanding the mechanisms of action of 5-aminosalicylic acid. Am J Gastroenterol. 2000;95(12): 3343-3345.

28. Stollman N, Magowan S, Shanahan F, Quigley EM; DIVA Investigator Group. A randomized controlled study of mesalamine after acute diverticulitis: results of the DIVA trial. J Clin Gastroenterol. 2013;47(7):621-629.

29. Parente F, Bargiggia S, Prada A, et al; “Gismi Study Group”. Intermittent treatment with mesalazine in the prevention of diverticulitis recurrence: a randomised multicentre pilot double-blind placebo-controlled study of 24-month duration. Int J Colorectal Dis. 2013;28(10):1423-1431.

30. Raskin JB, Kamm MA, Jamal MM, et al. Mesalamine did not prevent recurrent diverticulitis in phase 3 controlled trials. Gastroenterology. 2014;147(4):793-802.
31. Kruis W, Meier E, Schumacher M, Mickisch O, Greinwald R, Mueller R; German SAG-20 Study Group. Randomised clinical trial: mesalazine (Salofalk granules) for uncomplicated diverticular disease of the colon--a placebo-controlled study. Aliment Pharmacol Ther. 2013;37(7):680-690.

32. Comparato G, Fanigliulo L, Cavallaro LG, et al. Prevention of complications and symptomatic recurrences in diverticular disease with mesalazine: a 12-month follow-up. Dig Dis Sci. 2007;52(11):2934-2941.

33. Di Mario F, Aragona G, Leandro G, et al. Efficacy of mesalazine in the treatment of symptomatic diverticular disease. Dig Dis Sci. 2005;50(3):581-586.

34. Tursi A, Brandimarte G, Elisei W, et al. Randomised clinical trial: mesalazine and/or probiotics in maintaining remission of symptomatic uncomplicated diverticular disease--a double-blind, randomised, placebo-controlled study. Aliment Pharmacol Ther. 2013;38(7):741-751.

35. Tursi A, Brandimarte G, Giorgetti GM, Elisei W. Mesalazine and/or Lactobacillus casei in preventing recurrence of symptomatic uncomplicated diverticular disease of the colon: a prospective, randomized, open-label study. J Clin Gastroenterol. 2006;40(4):312-316.

36. Smith J, Humes D, Garsed K, et al. Mechanistic randomised control trial of mesalazine in symptomatic diverticular disease. Abstract OC-119 Table 1. Gut. 2012;61(Suppl 2):A51-A52.

37. Trepsi E, Colla C, Panizza P, et al. Ruolo terapeutico e profilattico della mesalazina (5-ASA) nella malattia diverticolare sintomatica del colon: follow-up a 4 anni [Therapeutic and prophylactic role of mesalazine (5-ASA) in symptomatic diverticular disease of the large intestine. 4 year follow-up results]. Minerva Gastroenterol Dietol. 1999;45(4):245-252. Italian [with English abstract].

38. Picchio M, Elisei W, Brandimarte G, et al. Mesalazine for the treatment of symptomatic uncomplicated diverticular disease of the colon and for primary prevention of diverticulitis: a systematic review of randomized clinical trials. J Clin Gastroenterol. 2016;50 Suppl 1:S64-S69.

39. Tursi A, Elisei W, Giorgetti GM, Aiello F, Brandimarte G. Inflammatory manifestations at colonoscopy in patients with colonic diverticular disease. Aliment Pharmacol Ther. 2011;33(3):358-365.

40. Nespoli L, Lo Bianco G, Uggeri F, et al. Effect of oral mesalamine on inflammatory response in acute uncomplicated diverticulitis. World $J$ Gastroenterol. 2015;21(27):8366-8372.

41. Khan MA, Ali B, Lee WM, Howden CW. Mesalamine does not help prevent recurrent acute colonic diverticulitis: meta-analysis of randomized, placebo-controlled trials. Am J Gastroenterol. 2016;111(4):579-581.

42. Elisei W, Tursi A. Recent advances in the treatment of colonic diverticular disease and prevention of acute diverticulitis. Ann Gastroenterol. 2016;29(1):24-32.

43. Wedel T, Barrenschee M, Lange C, Cossais F, Böttner M. Morphologic basis for developing diverticular disease, diverticulitis, and diverticular bleeding. Viszeralmedizin. 2015;31(2):76-82.

44. van Baal JO, Van de Vijver KK, Nieuwland R, et al. The histophysiology and pathophysiology of the peritoneum. Tissue Cell. 2017;49(1):95-105.

45. Schein M, Paladugu R. What's new in pathophysiology of peritonitis? Acta Chir Austriaca. 2000;32(26):162-166.

46. Sartelli M, Chichom-Mefire A, Labricciosa FM, et al. The management of intra-abdominal infections from a global perspective: 2017 WSES guidelines for management of intra-abdominal infections. World $J$ Emerg Surg. 2017;12(1):29.

47. Sartelli M, Catena F, Ansaloni L, et al. WSES Guidelines for the management of acute left sided colonic diverticulitis in the emergency setting. World J Emerg Surg. 2016;11:37.

48. Andersen JC, Bundgaard L, Elbrønd H, Laurberg S, Walker LR, Støvring $\mathrm{J}$; Danish Surgical Society. Danish national guidelines for treatment of diverticular disease. Dan Med J. 2012;59(5):c4453.

49. Gregersen R, Mortensen LQ, Burcharth J, Pommergaard HC, Rosenberg J. Treatment of patients with acute colonic diverticulitis complicated by abscess formation: A systematic review. Int J Surg. 2016;35:201-208.

50. Elagili F, Stocchi L, Ozuner G, Kiran RP. Antibiotics alone instead of percutaneous drainage as initial treatment of large diverticular abscess. Tech Coloproctol. 2015;19(2):97-103. 
51. Hemming A, Davis NL, Robins RE. Surgical versus percutaneous drainage of intra-abdominal abscesses. Am J Surg. 1991;161(5):593-595.

52. Neff CC, vanSonnenberg E, Casola G, et al. Diverticular abscesses: percutaneous drainage. Radiology. 1987;163(1):15-18.

53. Johnson WC, Gerzof SG, Robbins AH, Nabseth DC. Treatment of abdominal abscesses: comparative evaluation of operative drainage versus percutaneous catheter drainage guided by computed tomography or ultrasound. Ann Surg. 1981;194(4):510-520.

54. Ambrosetti P, Robert J, Witzig JA, et al. Incidence, outcome, and proposed management of isolated abscesses complicating acute left-sided colonic diverticulitis. A prospective study of 140 patients. Dis Colon Rectum. 1992;35(11):1072-1076.

55. Krukowski ZH, Matheson NA. Emergency surgery for diverticular disease complicated by generalized and faecal peritonitis: a review. $\mathrm{Br}$ J Surg. 1984;71(12):921-927.

56. Constantinides VA, Tekkis PP, Athanasiou T, et al. Primary resection with anastomosis vs. Hartmann's procedure in nonelective surgery for acute colonic diverticulitis: A systematic review. Dis Colon Rectum. 2006;49(7):966-981.

57. Myers E, Hurley M, O'Sullivan GC, Kavanagh D, Wilson I, Winter DC. Laparoscopic peritoneal lavage for generalized peritonitis due to perforated diverticulitis. Br J Surg. 2008;95(1):97-101.

58. Schultz JK, Yaqub S, Wallon C, et al; SCANDIV Study Group. Laparoscopic lavage vs primary resection for acute perforated diverticulitis: the SCANDIV randomized clinical trial. JAMA. 2015;314(13): 1364-1375.

59. Vennix S, Musters GD, Mulder IM, et al; Ladies trial collaborators. Laparoscopic peritoneal lavage or sigmoidectomy for perforated diverticulitis with purulent peritonitis: a multicentre, parallel-group, randomised, open-label trial. Lancet. 2015;386(10000):1269-1277.

60. Thornell A, Angenete E, Bisgaard T, et al. Laparoscopic lavage for perforated diverticulitis with purulent peritonitis: a randomized trial. Ann Intern Med. 2016;164(3):137-145. doi:10.7326/M15-1210.

61. Ceresoli M, Coccolini F, Montori G, Catena F, Sartelli M, Ansaloni L. Laparoscopic lavage versus resection in perforated diverticulitis with purulent peritonitis: a meta-analysis of randomized controlled trials. World J Emerg Surg. 2016;11(1):42.

62. Penna M, Markar SR, Mackenzie H, Hompes R, Cunningham C. Laparoscopic lavage versus primary resection for acute perforated diverticulitis: review and meta-analysis. Ann Surg. 2018;267(2):252-258.

63. Galbraith N, Carter JV, Netz U, et al. Laparoscopic lavage in the management of perforated diverticulitis: a contemporary meta-analysis. $J$ Gastrointest Surg. 2017;21(9):1491-1499.
64. Cirocchi R, Di Saverio S, Weber DG, et al. Laparoscopic lavage versus surgical resection for acute diverticulitis with generalised peritonitis: a systematic review and meta-analysis. Tech Coloproctol. 2017;21(2): 93-110.

65. Angenete E, Bock D, Rosenberg J, Haglind E. Laparoscopic lavage is superior to colon resection for perforated purulent diverticulitis-a meta-analysis. Int J Colorectal Dis. 2017;32(2):163-169.

66. Shaikh FM, Stewart PM, Walsh SR, Davies RJ. Laparoscopic peritoneal lavage or surgical resection for acute perforated sigmoid diverticulitis: a systematic review and meta-analysis. Int J Surg. 2017;38:130-137.

67. Ceresoli M, Coccolini F, Ansaloni L. Twelve-month results of laparoscopic lavage in perforated acute diverticulitis - Update of meta-analysis results. New evidences, which perspectives? J Trauma Acute Care Surg. 2017;83(6):1215-1216.

68. Coccolini F, Biffl W, Catena F, et al. The open abdomen, indications, management and definitive closure. World J Emerg Surg. 2015;10(1):32.

69. Coccolini F, Montori G, Ceresoli M, et al. The role of open abdomen in non-trauma patient: WSES Consensus Paper. World J Emerg Surg. 2017;12(1):39.

70. Shah SK, Jimenez F, Walker PA, et al. Peritoneal fluid: a potential mechanism of systemic neutrophil priming in experimental intra-abdominal sepsis. Am J Surg. 2012;203(2):211-216.

71. Kubiak BD, Albert SP, Gatto LA, et al. Peritoneal negative pressure therapy prevents multiple organ injury in a chronic porcine sepsis and ischemia/reperfusion model. Shock. 2010;34(5):525-534.

72. Emr B, Sadowsky D, Azhar N, et al. Removal of inflammatory ascites is associated with dynamic modification of local and systemic inflammation along with prevention of acute lung injury: in vivo and in silico studies. Shock. 2014;41(4):317-323.

73. Norbury KC, Moyer MP. Effect of negative pressure therapy on the inflammatory response of the intestinal microenvironment in a porcine septic model. Mediators Inflamm. 2015;2015:419841.

74. Perathoner A, Klaus A, Mühlmann G, Oberwalder M, Margreiter R, Kafka-Ritsch R. Damage control with abdominal vacuum therapy (VAC) to manage perforated diverticulitis with advanced generalized peritonitis--a proof of concept. Int J Colorectal Dis. 2010;25(6):767-774.

75. Kafka-Ritsch R, Birkfellner F, Perathoner A, et al. Damage control surgery with abdominal vacuum and delayed bowel reconstruction in patients with perforated diverticulitis Hinchey III/IV. $J$ Gastrointest Surg. 2012;16(10):1915-1922.

76. Sohn M, Agha A, Heitland W, Gundling F, Steiner P, Iesalnieks I. Damage control strategy for the treatment of perforated diverticulitis with generalized peritonitis. Tech Coloproctol. 2016;20(8):577-583.
Journal of Inflammation Research

\section{Publish your work in this journal}

The Journal of Inflammation Research is an international, peer-reviewed open access journal that welcomes laboratory and clinical findings on the molecular basis, cell biology and pharmacology of inflammation including original research, reviews, symposium reports, hypothesis formation and commentaries on: acute/chronic inflammation; mediators of

\section{Dovepress}

inflammation; cellular processes; molecular mechanisms; pharmacology and novel anti-inflammatory drugs; clinical conditions involving inflammation. The manuscript management system is completely online and includes a very quick and fair peer-review system. Visit http://www.dove press.com/testimonials.php to read real quotes from published authors. 